\title{
Brain CHID1 Expression Correlates with NRGN and CALB1 in Healthy Subjects and AD Patients
}

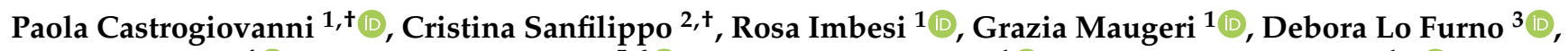 \\ Daniele Tibullo $^{4}\left(\mathbb{D}\right.$, Alessandro Castorina ${ }^{5,6}\left(\mathbb{D}\right.$, Giuseppe Musumeci ${ }^{1}(\mathbb{D})$ and Michelino Di Rosa ${ }^{1, *(1)}$
}

1 Department of Biomedical and Biotechnological Sciences, Human Anatomy and Histology Section, School of Medicine, University of Catania, 95123 Catania, Italy; pacastro@unict.it (P.C.); roimbesi@unict.it (R.I.); grazia.maugeri@libero.it (G.M.); gmusumeci@unict.it (G.M.)

2 IRCCS Centro Neurolesi Bonino Pulejo, Strada Statale 113, C.da Casazza, 98124 Messina, Italy; cristina.sanfilippo@irccsme.it

3 Department of Biomedical and Biotechnological Sciences, Physiology Section, University of Catania, 95123 Catania, Italy; lofurno@unict.it

4 Department of Drug Science, Biochemistry Section, University of Catania, 95125 Catania, Italy; d.tibullo@unict.it

5 Laboratory of Cellular and Molecular Neuroscience (LCMN), School of Life Sciences, Faculty of Science, University of Technology Sydney, Broadway, NSW 2007, Australia; alessandro.Castorina@UTS.edu.au

6 Laboratory of Neural Structure and Function (LNSF), School of Medical Sciences (Anatomy \& Histology), Faculty of Medicine and Health, University of Sydney, Sydney, NSW 2006, Australia

* Correspondence: mdirosa@unict.it; Tel.: +39-095-378-2041

+ These authors contributed equally to this work.

check for updates

Citation: Castrogiovanni, P.; Sanfilippo, C.; Imbesi, R.; Maugeri, G.; Lo Furno, D.; Tibullo, D.; Castorina,

A.; Musumeci, G.; Di Rosa, M. Brain CHID1 Expression Correlates with NRGN and CALB1 in Healthy Subjects and AD Patients. Cells 2021, 10, 882. https://doi.org/10.3390/ cells10040882

Academic Editor: Nady Braidy

Received: 22 March 2021

Accepted: 12 April 2021

Published: 13 April 2021

Publisher's Note: MDPI stays neutral with regard to jurisdictional claims in published maps and institutional affiliations.

Copyright: (c) 2021 by the authors. Licensee MDPI, Basel, Switzerland. This article is an open access article distributed under the terms and conditions of the Creative Commons Attribution (CC BY) license (https:/ / creativecommons.org/licenses/by/ $4.0 /)$.
Abstract: Alzheimer's disease is a progressive, devastating, and irreversible brain disorder that, day by day, destroys memory skills and social behavior. Despite this, the number of known genes suitable for discriminating between $\mathrm{AD}$ patients is insufficient. Among the genes potentially involved in the development of $\mathrm{AD}$, there are the chitinase-like proteins (CLPs) CHI3L1, CHI3L2, and CHID1. The genes of the first two have been extensively investigated while, on the contrary, little information is available on CHID1. In this manuscript, we conducted transcriptome meta-analysis on an extensive sample of brains of healthy control subjects $(n=1849)(N D H C)$ and brains of AD patients $(n=1170)$ in order to demonstrate CHID1 involvement. Our analysis revealed an inverse correlation between the brain CHID1 expression levels and the age of NDHC subjects. Significant differences were highlighted comparing CHID1 expression of NDHC subjects and AD patients. Exclusive in AD patients, the CHID1 expression levels were correlated positively to calcium-binding adapter molecule 1 (IBA1) levels. Furthermore, both in NDHC and in AD patient's brains, the CHID1 expression levels were directly correlated with calbindin 1 (CALB1) and neurogranin (NRGN). According to brain regions, correlation differences were shown between the expression levels of CHID1 in prefrontal, frontal, occipital, cerebellum, temporal, and limbic system. Sex-related differences were only highlighted in NDHC. CHID1 represents a new chitinase potentially involved in the principal processes underlying Alzheimer's disease.

Keywords: CHID1; Alzheimer's disease; chitinases; bioinformatics

\section{Introduction}

Neurodegeneration indicates a progressive structural, functional, and molecular alteration of neurons, with consequent progressive cell degeneration. As regards, neurodegenerative diseases, such as amyotrophic lateral sclerosis, Alzheimer's disease (AD), Parkinson's disease, and Huntington's disease, they are characterized by neurodegenerative phenomena [1]. The molecular mechanisms that regulate these diseases are also present in aging and neurodegenerative diseases. The damage to neurons revealed during aging can be considered to be exacerbated in neurodegenerative diseases [2]. The neurodegenerative 
processes are triggered by genetic predisposition factors linked to intrinsic susceptibility and epigenetic mechanisms associated with environmental factors, with aging itself increasing the risk [2]. Being able to understand the principal molecules that regulate the cellular mechanisms of the neuroglia represents a new strategy to counteract the development and progression of neurodegenerative diseases. Among the main neurodegenerative diseases, Alzheimer's disease (AD) represents one of the most common with still unknown pathogenesis [3]. Recently, several investigations have demonstrated the decisive role of both neuroinflammation and the toxicity carried out by amyloid-beta $(\mathrm{A} \beta)$ peptide on central nervous system (CNS) neurons [4]. A $\beta$ peptides tend to precipitate forming microaggregates, commonly called "soluble A $\beta$ oligomers", protofibrils, and fibrils which tend to accumulate in the brains of AD patients, forming the more well-known insoluble "amyloid plaques" [5]. Consequently, the accumulation of A $\beta$ peptides results in neuron death and local immune activation, which leads to synaptic and cognitive dysfunctions. Several proteins, such as chitinases [6], calcium-binding adapter molecule 1 (IBA1) [7], platelet endothelial cell adhesion molecule (CD31) [8], and calbindin 1 (CALB1) [9], could be considered new potential markers of the cellular architecture alteration of the nervous system parenchyma.

Mammalian chitinases consisting of chitinase acid (CHIA) [10], chitotriosidase (CHIT1) [11], chitinase 3-like protein 1 (CHI3L1) [12], chitinase 3-like protein 2 (CHI3L2) [13], and chitinase domain-containing protein 1 (CHID1) [14] exert important biological roles in different cell types, such as polarized macrophages [15], dendritic cells [16], osteoclasts [17], and several cells with high proliferative activity $[18,19]$. CHI3L1, CHI3L2, and CHID1 are chitin-binding proteins (CLPs) that lack chitin-hydrolyzing activity but possess cytokinelike and growth factor-like properties. The expression of CLPs has been related to several pathological phenomena with an inflammatory etiogenesis [20]. In recent years, different roles have been attributed to CLPs, such as tissue remodeling during inflammation, differentiation, and maturation of macrophages. Its high levels have been associated with various pathological disorders such as diabetes [21], osteoarthritis [22], and asthma [23]. Very little is known about the role of CHID1, which is also known as stabilin-1-interacting chitinase-like protein (SI-CLP). It has been shown that interact with the protein STAB1. The protein structure presents carbohydrate binding sites, which could be involved in carbohydrate catabolysis. CHID1 is a marker for alternative macrophage activation. CHID1 was abundantly detected in bronchoalveolar lavage from patients with chronic inflammatory disorders of the respiratory tract and human peripheral blood leukocytes [24]. CHID1 secretion is mediated by its interaction with the endocytic/sorting receptor stabilin- 1 and is activated by Th2 cytokines [24]. Our recent papers detected the existence of CHID1 in pediatric brain tumors [14], macrophages infected with HIV-1 virus [25], and LOAD brain patients $[13,26]$. Although CHID1 was initially associated with alternative activated macrophages, evidence suggests that during neurodegenerative processes, its expression is abundant in the nucleoplasm of microglia [27]. Currently, there is no exhaustive information on its possible correlation with markers of neuroimmune activation, alteration of the blood-brain barrier (BBB), and neuronal transmission. Starting from this data, we selected IBA1, CD31, and CALB1, new neurodegeneration markers, in order to identify potential a correlation with CHID1 in the CNS.

Allograft inflammatory factor 1 (AIF-1), also known as ionized calcium-binding adapter molecule 1 (IBA1), is mainly produced by the innate immune cells specifically in monocyte-derived macrophages [28], neutrophils [29], and microglia [30] in response to the cytokine IFN- $\gamma$ [31]. It has been shown to be overexpressed during the activation of the immune cells in CNS injuries. As for its distinctive characteristics, it can be considered a glia marker of activation [32]. Recently, it has been hypothesized that IBA1 can regulate microgliosis by determining the scavenger of cellular debris, produced as waste during neurodegenerative processes, the recruitment of oligodendrocytes, and the reorganization of CNS cellular structure [33]. 
Platelet endothelial cell adhesion molecule (PECAM-1) is also known as cluster of differentiation 31 (CD31), highly expressed on neutrophils, monocytes, lymphocytes, platelets, and endothelial cells [34]. It was demonstrated that it plays a role in cell adhesion by mediating the diapedesis of the immune system cells through the modification of the vascular wall, suggesting a role potential as a vascular integrity marker [34]. Currently, it has been shown to have direct involvement in the regulation of BBB integrity [35]. Furthermore, it has also been shown that CD31 plays a relevant role in A $\beta$-related cerebral vascular disorders pathogenesis, such as AD [36], and is involved in the pathological molecular mechanism of neurological disease and in neuroHIV neuroinflammation [37].

Calbindin 1 (CALB1) is a calcium-binding and buffering protein, and it has been highlighted that it has a relevant role in preventing neuron death [38]. Alterations in the expression levels of this gene have been highlighted in patients with Huntington's disease [39]. Due to its function, an increase in its expression has been associated with a protective role in various neurological diseases. Actually, the increase in CALB1 protein induces neurite outgrowth in dopaminergic neuronal cells and provides protection to dopaminergic neurons against pathological processes in Parkinson's disease [40]. With aging, calbindin-containing neurons cells in the basal forebrain gradually die, and this process is exacerbated in AD patients [41]. During human immunodeficiency virus encephalitis (HIVE), neuronal damage could be produced by CALB1 reduction and increased neuron intracellular calcium [42].

Neurogranin (NRGN or Ng) is a 78-amino-acid-long post-synaptic protein, highly expressed in the brain, predominantly in dendritic spines of neurons in the amygdala, hippocampus, cerebral cortex, and other associative cortical areas $[43,44]$. Its protein actively participates in signal transduction in the protein kinase $C$ signaling pathway. The main function is carried out at a postsynaptic level, regulating the availability of calmodulin, binding to it via an IQ motif (amino acid 33-46) in the absence of calcium. It has been shown that the mRNA and protein levels in the hippocampus decrease with age and are related to CNS dysfunction [45]. Its concentration in cerebrospinal fluid (CSF) is considered an index of synaptic dysfunction in neurodegeneration. High levels have been shown in the CSF of AD patients compared to healthy controls [46]. Data analysis from brain tissue indicates a decrease of NRGN concentrations in both the frontal cortex [47], parietal cortex [48], and hippocampus [47]. There is a direct link between NRGN and CHI3L1 so as to be able to consider the two proteins of the independent markers of synaptic degeneration and neuroinflammation in AD [49].

In this study, we investigated the expression levels of CHID1 in NDHCS subjects and brain biopsies of AD patients, and the possible correlations with aging, in different brain regions. To do this, we collected and clustered the transcriptome of more than 3000 brain samples present in NCBI in the GEODataSet section. Furthermore, we hypothesized that the CHID1 expression levels in the AD patient brain samples were correlated with markers of microglial activation (IBA1), vascular integrity (CD31), and neuronal death (CALB1) and neurogranin $(N R G N)$, all phenomena characterizing the brain of AD patients.

\section{Materials and Methods}

\subsection{Data Selection}

For our analysis, we have collected 18 microarray datasets of brain data biopsies of nondemented subjects who died from causes not attributable to neurodegenerative diseases, and deceased patients suffering from AD. The transcriptome datasets were downloaded from NCBI Gene Expression Omnibus (GEO) database (http:/ / www.ncbi.nlm.nih.gov / geo/, accessed on 9 January 2021) [50]. MeSH terms "Brain region", "Human", and "Alzheimer's disease" were used to identify human potential datasets of interest. The selected datasets are shown in Table 1. 
Table 1. Datasets selected.

\begin{tabular}{cccccccc}
\hline $\mathbf{N}^{\circ}$ & Dataset & Organism & Platform & & NDHC & AD & References \\
\hline 1 & GSE33000 & Homo sapiens & GPL4372 & HBTRC & 144 & 310 & {$[51]$} \\
2 & GSE28894 & Homo sapiens & GPL6104 & NIA & 29 & 0 & {$[52]$} \\
3 & GSE35978 & Homo sapiens & GPL6244 & SMRI & 13 & 0 & {$[53]$} \\
4 & GSE15745 & Homo sapiens & GPL6104 & UMBB & 132 & 0 & {$[54]$} \\
5 & GSE44772 & Homo sapiens & GPL4372 & HBTRC & 273 & 387 & {$[55]$} \\
6 & GSE36192 & Homo sapiens & GPL6947 & NIA & 379 & 0 & {$[56]$} \\
7 & GSE60862 & Homo sapiens & GPL5175 & UKBEC & 226 & 0 & {$[57]$} \\
8 & GSE118553 & Homo sapiens & GPL10558 & MRC-LBB & 72 & 167 & {$[58]$} \\
9 & GSE25219 & Homo sapiens & GPL5175 & BTBDDUM & 27 & 0 & {$[59]$} \\
10 & GSE71620 & Homo sapiens & GPL11532 & PBTDP & 208 & 0 & {$[60]$} \\
11 & GSE5392 & Homo sapiens & GPL96 & SMRIC & 3 & 0 & {$[61]$} \\
12 & GSE36980 & Homo sapiens & GPL6244 & KU & 47 & 32 & {$[62]$} \\
13 & GSE26927 & Homo sapiens & GPL6255 & BNEN & 4 & 11 & {$[63]$} \\
14 & GSE84422 & Homo sapiens & GPL570 & MSBB & 28 & 74 & {$[64]$} \\
15 & GSE5281 & Homo sapiens & GPL570 & ADCs & 74 & 87 & {$[65]$} \\
16 & GSE48350 & Homo sapiens & GPL570 & ADC & 93 & 80 & {$[66]$} \\
17 & GSE11882 & Homo sapiens & GPL570 & MSBB & 93 & 0 & {$[67]$} \\
18 & GSE28146 & Homo sapiens & GPL570 & BBADRCUK & 8 & 22 & {$[68]$} \\
\hline
\end{tabular}

Harvard Brain Tissue Resource Center (HBTRC); Mount Sinai Medical Center Brain Bank (MSBB); National Institute on Aging (NIA); Stanley Medical Research Institute (SMRI); University of Maryland Brain Bank (UMBB); UK Brain Expression Consortium (UKBEC); Medical Research Council (MRC) London Neurodegenerative Diseases Brain Bank (from now on referred to as MRC-LBB); University of Pittsburgh's Brain Tissue Donation Program (PBTDP); Neuropathology Consortium of the Stanley brain collection (Stanley Medical Research Institute, US) (SMRIC); Kyushu University (KU); BrainNet Europe network (BNEN); Mount Sinai/JJ Peters VA Medical Center Brain Bank (MSBB); Alzheimer's Disease Centers (ADCs); Brain Bank of the Alzheimer's Disease Research Center at the University of Kentucky (BBADRCUK); Brain and Tissue Bank for Developmental Disorders at the University of Maryland (BTBDDUM); NDHC = non-demented healthy controls subjects; $\mathrm{AD}=$ Alzheimer's disease patients.

Each brain with $\mathrm{AD}$ was age-matched to a healthy brain to rule out any differences due to routine aging. Furthermore, we stratified the samples according to sex and age as shown in Table 2. Five groups were obtained: middle-age (53-65 years), senior (66-75 years), elderly (76-89 years), nonagenarian (90-99 years) and centenarian (>100 years) [12].

Table 2. Sample stratification.

\begin{tabular}{cccc}
\hline & Age Stage & NDHCS & AD \\
\hline 1 & $53-65$ middle-age & $734=582$ male +152 female & $59=34$ male +25 female \\
2 & $65-75$ senior & $425=291$ male +134 female & $219=75$ male +144 female \\
3 & $76-89$ elderly & $493=328$ male +165 female & $639=361$ male +278 female \\
4 & $90-99$ nonagenarian & $179=61$ male +118 female & $235=187$ male +48 female \\
5 & $>100$ centenarian & $22=4$ male +18 female & $18=13$ male +5 female \\
& Total sample & 1853 & 1170 \\
\hline NDHC $=$ non-demented healthy controls subjects; AD
\end{tabular}

NDHC = non-demented healthy controls subjects; $\mathrm{AD}=$ Alzheimer's disease patients.

All brains sample analyzed were grouped into 8 main brain regions (prefrontal, frontal, occipital, cerebellum, temporal, cingulate, diencephalon, limbic system). Complete brain regions details examined are presented in Table 3. 
Table 3. Brain regions analyzed.

\begin{tabular}{|c|c|c|c|c|c|}
\hline $\mathbf{N}^{\circ}$ & Brain Regions & Abbreviations & Brain Portions & $\mathbf{n}^{\circ}$ of Sample & Age \\
\hline 1 & prefrontal & PFC & $\begin{array}{l}\text { prefrontal cortex; dorsolateral prefrontal } \\
\text { cortex; dorsolateral prefrontal cortex; medial } \\
\text { prefrontal cortex; ofc (orbitofrontal cortex); } \\
\text { orbitofrontal cortex; orbital prefrontal cortex; } \\
\text { ventral forebrain; ventrolateral cortex; } \\
\text { ventrolateral prefrontal cortex }\end{array}$ & $\begin{array}{l}1045=784 \text { male }+ \\
261 \text { female }\end{array}$ & $51.18 \pm 21$ \\
\hline 2 & frontal & FC & $\begin{array}{l}\text { frontal cortex frontal pole (Brodmann area } \\
\qquad 9,10) ; \text { medial frontal cortex }\end{array}$ & $\begin{array}{l}868=577 \text { male }+ \\
291 \text { female }\end{array}$ & $51.07 \pm 26.08$ \\
\hline 3 & occipital & OC & $\begin{array}{c}\text { occipital cortex; primary visual cortex; } \\
\text { visual cortex }\end{array}$ & $\begin{array}{l}286=207 \text { male }+ \\
79 \text { female }\end{array}$ & $55.16 \pm 25.44$ \\
\hline 4 & cerebellum & $\mathrm{CB}$ & $\begin{array}{l}\text { cerebellar cortex; cerebellum; upper (rostral) } \\
\text { rhombic lip }\end{array}$ & $\begin{array}{l}1009=693 \text { male }+ \\
316 \text { female }\end{array}$ & $50.9 \pm 24.52$ \\
\hline 5 & temporal & $\mathrm{TP}$ & $\begin{array}{l}\text { inferior temporal cortex; primary auditory } \\
\text { cortex; superior temporal cortex; superior } \\
\text { temporal cortex (Brodmann area 22); temporal } \\
\text { cortex; ventral head of the caudate nucleus }\end{array}$ & $\begin{array}{l}466=174 \text { male }+ \\
292 \text { female }\end{array}$ & $47.77 \pm 29.01$ \\
\hline 6 & cingulate & CYN & $\begin{array}{l}\text { anterior cingulate; caudal ganglionic eminence; } \\
\text { lateral ganglionic eminence; medial ganglionic } \\
\text { eminence; medial temporal gyrus; postcentral } \\
\text { gyrus; posterior cingulate; posterior cingulate } \\
\text { cortex; subpial grey matter lesions from the } \\
\text { frontal gyri; superior frontal gyrus }\end{array}$ & $\begin{array}{l}319=196 \text { male }+ \\
123 \text { female }\end{array}$ & $61.35 \pm 22.55$ \\
\hline 7 & diencephalon & DIE & $\begin{array}{c}\text { basal ganglia; dorsal thalamus; putamen; } \\
\text { striatum; nucleus accumbens; substantia nigra; } \\
\text { thalamus; mediodorsal nucleus of } \\
\text { the thalamus }\end{array}$ & $\begin{array}{l}450=304 \text { male }+ \\
146 \text { female }\end{array}$ & $55.41 \pm 24.47$ \\
\hline 8 & limbic system & LS & amygdala; entorhinal cortex; hippocampus & $\begin{array}{c}563=356 \text { male }+ \\
207 \text { female }\end{array}$ & $56.83 \pm 26.31$ \\
\hline
\end{tabular}

\subsection{Clinical and Neuropathological Criteria}

A total of 1853 data points from frozen tissue samples were selected belonging to subjects who did not die from causes related to neurological diseases that we have identified as non-demented healthy controls subjects (NDHC) (70.63 \pm 12.45 years) and 1170 samples taken from $\mathrm{AD}$ patients $(82.03 \pm 9.29$ years). Most of the samples analyzed were obtained from public brain databases (Table 1). Postmortem interval (PMI), sample $\mathrm{pH}$, and RNA integrity number (RIN) were elements of pre-selection by the authors of the reference microarray datasets and, subsequently, were bases for further exclusion in our analysis. For the diagnosis of $\mathrm{AD}$, we took into consideration the investigations carried out by the authors of the individual datasets (Consortium to Establish a Registry for Alzheimer's Disease (CERAD) guidelines, progressive decline in memory, cognitive deficits in two or more areas, MMSE , CDR, Braak stage, general and regional atrophy, gray and white matter atrophy, ventricular enlargement, and cataloged neuropathological diagnosis by pathologists based on e.g., neurofibrillary tangle (NFT) counts). As regards the cognitive integrity of the healthy subjects included in our analysis, we took into account the investigations and cognitive tests carried out by the authors of the microarray datasets listed in Table 1 (memory complaints, history of memory complaints, normal cognitive function documented by scoring age and education adjusted, mini-mental status examination (MMSE), and global clinical dementia rating, CDR).

\subsection{Data Processing and Experimental Design}

In order to process and identify significantly differentially expressed genes (SDEG) in all selected datasets, we used MultiExperiment Viewer $(\mathrm{MeV})$ software (The Institute 
for Genomic Research (TIGR), J. Craig Venter Institute, USA). In cases where multiple genes probes insisted on the same GeneID, we used those with the highest variance. The significance threshold level for all datasets was $p<0.05$. Statistically significant genes were selected for further analysis. For all datasets we performed a statistical analysis with GEO2R, applying a Benjamini and Hochberg FDR (false discovery rate) to adjust $p$ values for multiple comparisons [69-72].

\subsection{Statistical Analysis}

For statistical analysis, Prism 8.0.2 software (GraphPad Software, San Diego, CA, USA) was used. Based on Shapiro-Wilk test, almost all data were normal, so parametric tests were used. Significant differences between groups were assessed using the ordinary one-way ANOVA test, and Tukey's multiple comparisons test correction was performed to compare data between all groups. Correlations were determined using Pearson correlation. All tests were two-sided, and significance was determined at adjusted $p$ value of 0.05 . All MD selected were transformed for the analysis in Z-score intensity signal. Z score is constructed by taking the ratio of weighted mean difference and combined standard deviation according to Box and Tiao (1992) [73]. The application of a classical method of data normalization, z-score transformation, provides a way of standardizing data across a wide range of experiments and allows the comparison of microarray data independent of the original hybridization intensities. The $\mathrm{z}$-score is considered a reliable procedure for this type of analysis and can be considered a state-of-the-art method, as demonstrated by the numerous articles [74-85].

The efficiency of each biomarker was assessed by the receiver operating characteristic (ROC) curve analyses [86,87]. Nonparametric ROC curves analyzed AD vs. NDHC. The area under the ROC curve (AUC) and its 95\% confidence interval (95\% CI) indicate diagnostic efficiency. The accuracy of the test with the percent error is reported [88].

\section{Results}

\subsection{Sex-Dependent Differences in CHID1 Brain Expression of NDHC Subjects and AD Patients}

For our analysis, we have collected 1170 AD patients and 1849 non-demented healthy control subjects (NDHC) in order to verify the CHID1 expression levels. The samples were stratified into five groups according to age (middle-age, senior, elderly, nonagenarian, and centenarian). A summary of sample sizes included in this study is described in Table 2.

Brain CHID1 RNA expression levels were significantly lower in patients with AD as compared to NDHC subjects (Figure 1A,B). When comparing the whole-brain CHID1 expression levels of NDHC and AD according to the sex, we found no significant difference (Figure 1B).

There was a moderate inverse correlation between CHID1 brain expression levels in NDHC and age $(r=-0.1050, p<0.0001)$ (Figure 2A). A significant inverse correlation in CHID1 brain expression levels has been observed in both males $(\mathrm{r}=-1051, p=0.0002)$ (Figure 2B) and females ( $\mathrm{r}=-1019, p=0.0135$ ) (Figure $2 \mathrm{C}$ ) of NDHC subjects.

The correlation analysis between CHID1 expression levels and age in the brains of AD patients showed conflicting results (Figure 3). Brain expression of CHID1 did not correlate with age in AD patients ( $r=0.050, p=n s$ ) (Figure 3A). In AD male patients, we observed the same trend for all samples $(r=0.082, p=n s)$ (Figure 3B), while in females, a positive correlation with age was highlighted $(r=0.1501, p<0.00001)$ (Figure 3C).

\subsection{Neurodegeneration Markers Correlated with CHID1 Expression Levels in the CNS}

In dividing the samples of the $1170 \mathrm{AD}$ patients according to sex, 500 were males and 670 were females, and of the 1849 NDHC subjects, 1264 were males and 585 were females (Table 2). We sorted the samples according to gender and carried out a comparative analysis of expression levels.

The analysis of 1849 NDHC brains show that the CHID1 expression levels were correlated with CD31 ( $\mathrm{r}=-0.061, p=0.0082)$, CALB1 $(\mathrm{r}=0.2671, p<0.0001)$, and NRGN 
$(\mathrm{r}=-0.2538, p<0.0001)$. No correlation was observed between CHID1 and IBA1 expression levels (Figure $4 \mathrm{~A}$ ).

In the 1264 NDHC male brain samples, we showed that the CHID1 expression levels were correlated with CD31 ( $\mathrm{r}=-0.097, p=0.0005)$, CALB1 $(\mathrm{r}=0.2413, p<0.0001)$, and $N R G N(r=0.2661, p<0.0001)$ (Figure 4B). In addition, for NDHC male brains, no correlation was observed between CHID1 and IBA1.

(A)

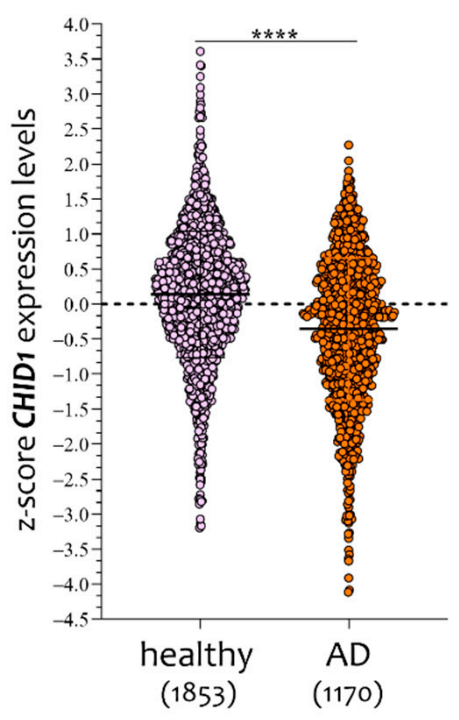

(B)

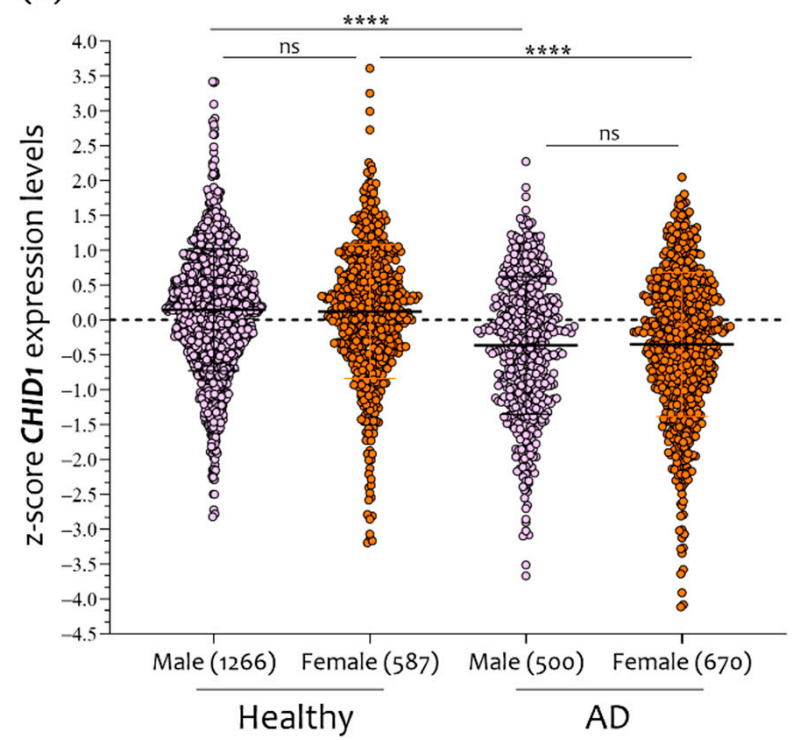

Figure 1. Sex-dependent difference in CHID1 brain expression of NDHC subjects. Analysis of CHID1 expression levels in $1853 \mathrm{NDHC}$ brains subjects and $1170 \mathrm{AD}$ brains patients (A), placed in order according to the sex (B). Data in the figure are indicated as z-score intensity expression levels and presented graphically as violin dot plots. $p$ values $<0.05$ were considered to be statistically significant (ns = not significant; ${ }^{* * * *} p<0.00001$ ).

(A)

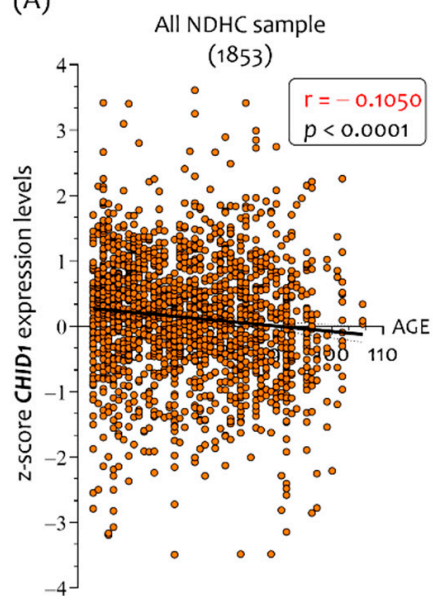

(B)

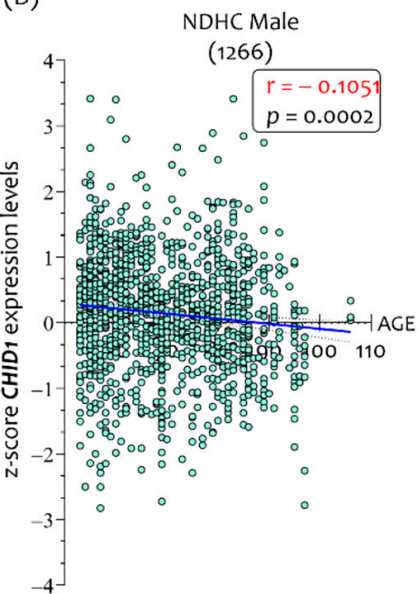

(C)

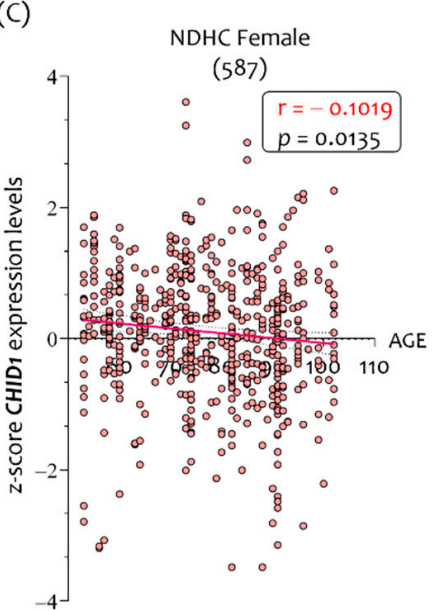

Figure 2. Correlation analysis between CHID1 brain expression levels and the age of NDHC subjects. Correlation analysis between CHID1 and the age of NDHC subjects (A), sorted according to the sex in brain samples of 1266 males (B) and 587 females (C). Data in the figure are indicated as z-score intensity expression levels and presented graphically as dot plots. $p$ values $<0.05$ were considered to be statistically significant. 
(A)

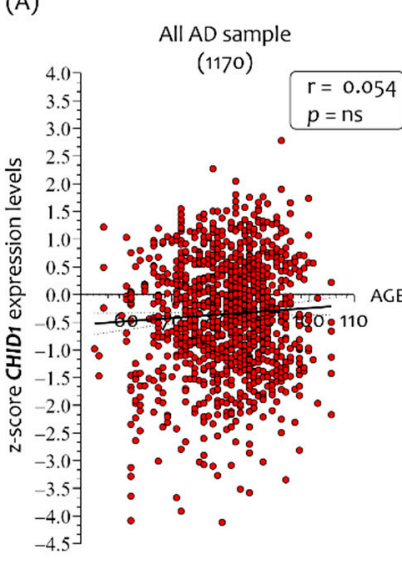

(B)

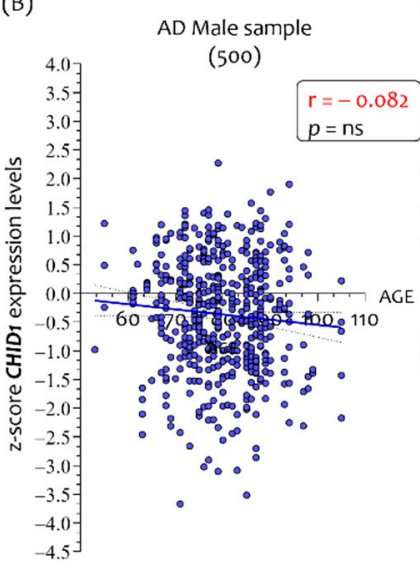

(C)

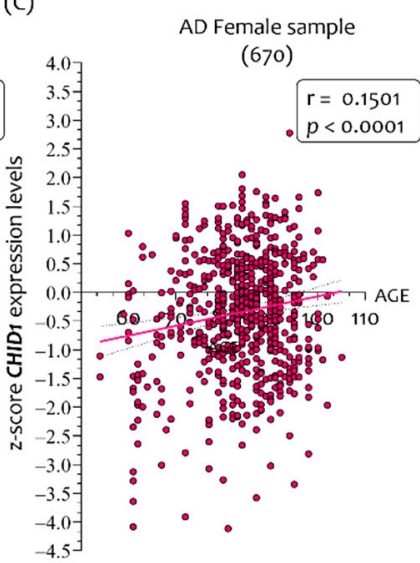

Figure 3. Correlation analysis between CHID1 brain expression levels and the age of AD patients from which the samples were taken. Correlation analysis between CHID1 and the age of AD patients (A), sorted according to the sex in brains of 1266 males (B) and 587 females (C). Data in the figure are indicated as z-score intensity expression levels and presented graphically as dot plots. $p$ values $<0.05$ were considered to be statistically significant.

(A)

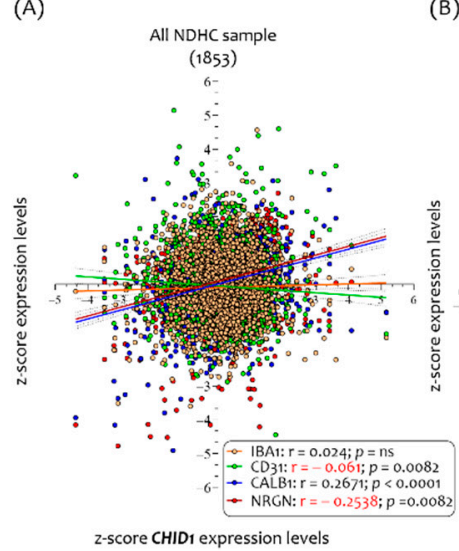

(B)

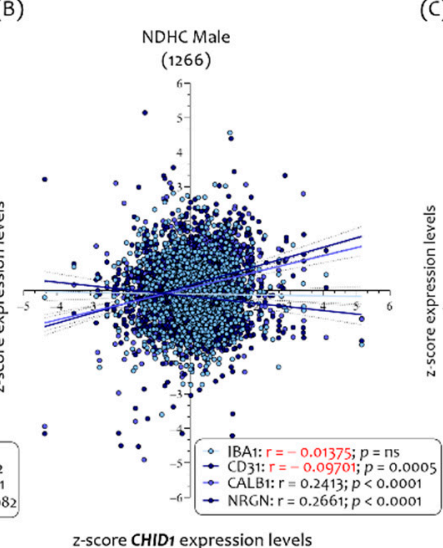

(C)

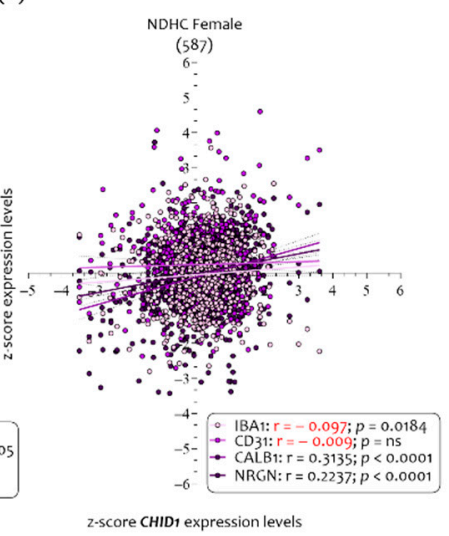

Figure 4. Correlation analysis between brain CHID1 expression levels and neurological markers in NDHC subjects. Analysis of the correlation between the CHID1, IBA1, CD31, CALB1, and NRGN expression levels in all brains (1853) (A), and in brains sorted according to 1266 males (B) and 587 females (C) belonging to NDHC subjects. Data in the figure are indicated as z-score intensity expression levels and presented graphically as dot plots. $p$ values $<0.05$ were considered to be statistically significant.

When we analyzed the 585 NDHC female brain samples, we demonstrated that CHID1 expression levels correlated both to CALB1 $(\mathrm{r}=0.3135, p<0.0001)$ and to NRGN $(\mathrm{r}=0.2237$, $p<0.0001)$, but not to CD31 ( $\mathrm{r}=-0.009, p=\mathrm{ns}$ ) (Figure 4B). Contrary to data highlighted in the brains of NDHC males, CHID1 expression was negatively correlated with IBA1 in females $(r=-0.097, p=0.0184)$ (Figure 4C).

Partially overlapping results were highlighted in AD brains. The analysis of 1170 AD brains show that CHID1 expression levels were correlated with IBA1 $(\mathrm{r}=0.2013, p<0.0001)$, CD31 $(\mathrm{r}=-0.09, p=0.0019)$, CALB1 $(\mathrm{r}=0.1249, p<0.0001)$, and NRGN $(\mathrm{r}=0.1544, p<0.0001)$ (Figure 5A). 

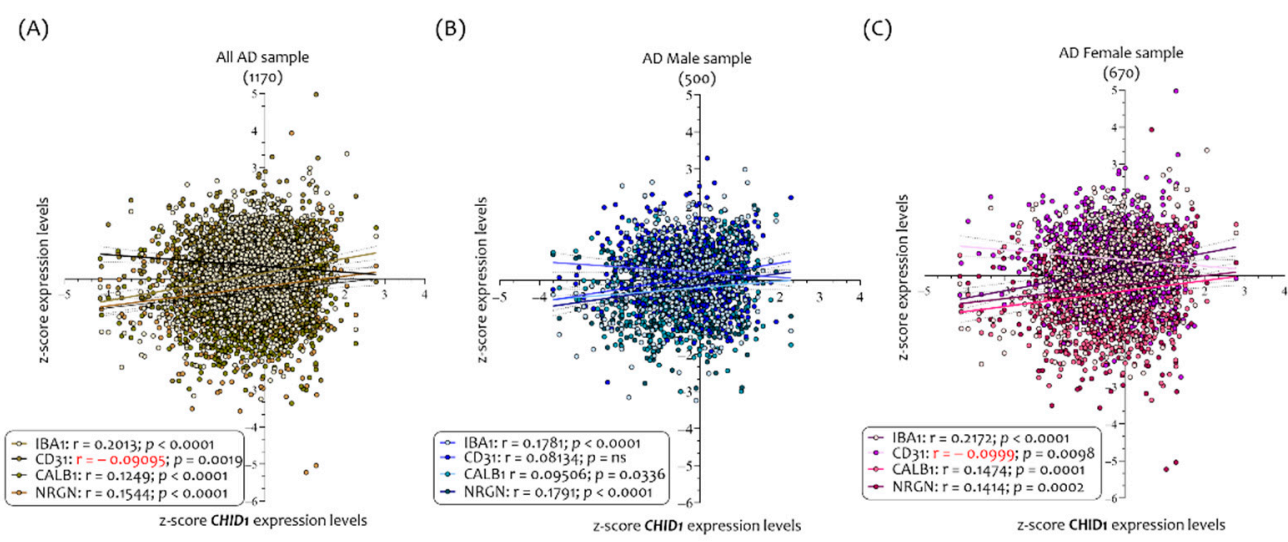

Figure 5. Correlation analysis between $C H I D 1$ brain expression levels and neurological markers in AD patients. Analysis of correlation between the CHID1, IBA1, CD31, CALB1, and NRGN expression levels in all brains (1170) (A), and in brains sorted in 500 males (B) and 670 females (C), belonging to AD patients. Data in the figure are indicated as z-score intensity expression levels and presented graphically as dot plots. $p$ values $<0.05$ were considered to be statistically significant.

In analyzing the CHID1 expression level in the brains of $500 \mathrm{AD}$ males, we have been able to ascertain that its expression levels were correlated with $I B A 1(\mathrm{r}=0.1781, p<0.0001)$, CALB1 $(\mathrm{r}=0.095, p=0.036)$, and NRGN $(\mathrm{r}=0.1791, p<0.00001)$ but not to CD31 $(\mathrm{r}=0.081$, $p=\mathrm{ns}$ ) (Figure 5B).

Regarding the $670 \mathrm{AD}$ female brains, the results show that the CHID1 expression levels correlated with IBA1 $(\mathrm{r}=0.2172, p<0.0001)$, CD31 ( $\mathrm{r}=-0.09, p=0.0098)$, CALB1 $(\mathrm{r}=0.1474, p=0.0001)$, and NRGN $(\mathrm{r}=0.1414, p=0.0002)$ (Figure $5 \mathrm{C})$.

\subsection{CHID1 Levels Are Differentially Expressed in Eight Brain Regions}

We deepened our investigation by comparing the expression levels of CHID1 in the different brain regions according to sex. Fifty-eight brain portions were grouped into 8 main brain regions (prefrontal, frontal, occipital, cerebellum, temporal, cingulate, diencephalon, and limbic system). Complete brain regions details examined in this paper are available in Table 3.

In analyzing the NDHC subjects' eight brain regions, we observed that the highest CHID1 expression levels were in the occipital cortex, while the lowest were in the cingulate cortex (Figure 6A). As regards the AD patients' eight brain regions, we observed that the highest CHID1 expression levels were in the diencephalon, while the lowest were in the temporal cortex (Figure 6B). Significant differences in CHID1 expression levels were found by comparing the frontal cortex $(p<0.0001, p=0.001)$, prefrontal $(p<0.0001, p=0.001)$, occipital $(p<0.0001, p<0.0001),(p=0.001)$, and temporal $(p<0.0001, p<0.001)$ brain regions with the cingulate and limbic system in NDHC subjects (Figure 6A). Furthermore, we observed that CHID1 expression in the cerebellum was significantly lower than in the occipital lobe $(p<0.01)$ (Figure 6A).

As regards the AD patients' brain regions, we observed significant differences in CHID1 expression levels by comparing the cerebellum $(p=0.001)$, temporal $(p<0.0001)$, cingulate $(p=0.001)$, occipital $(p=0.01)$, and prefrontal $(p<0.0001)$ brain regions with the diencephalon (Figure 6B). Furthermore, we observed that CHID1 expression in the limbic system was significantly lower than in the diencephalon $(p<0.001)$ (Figure $6 \mathrm{~B})$.

In analyzing the CHID1 expression levels in the eight brain regions in NDHC subjects and AD patients, we highlighted a significant difference only in NDHC subjects' limbic system region, in which males had significantly lower levels than females $(p<0.0001)$ (Figure S1A). No significant difference between the sexes was observed in the different brain regions of AD patients (Figure S1B). 
(A)

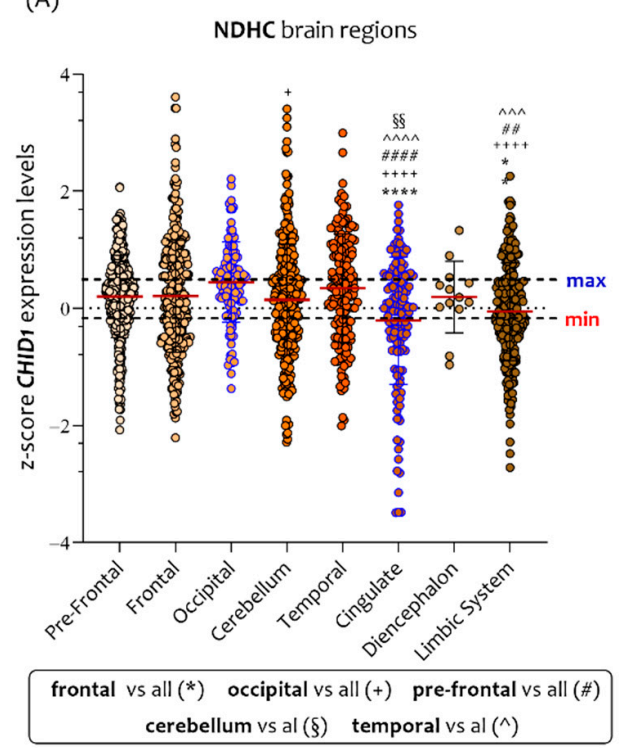

(B)

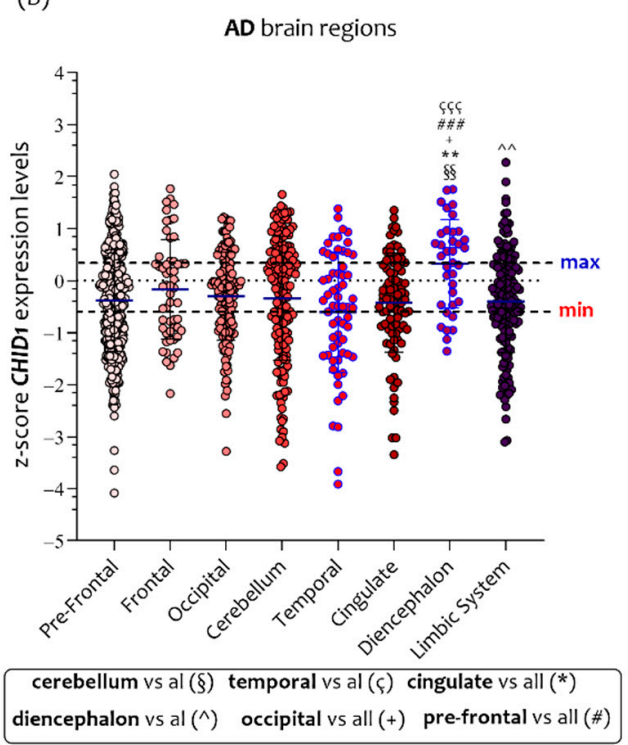

Figure 6. CHID1 levels are differentially expressed in brain regions of NDHC subjects and AD patients. Analyzing the NDHC individual brain regions, we observed that the highest CHID1 expression levels were in the occipital cortex, while the lowest in the region of cingulate (A). As regards the $\mathrm{AD}$ patients' brain regions, we observed that the highest $\mathrm{CHID1}$ expression levels were in the diencephalon, while the lowest at the region of the temporal cortex (B). See the text for details. Data in the figure are indicated as z-score intensity expression levels and presented graphically as violin dot plots. $p$ values $<0.05$ were considered to be statistically significant (ns = not significant;

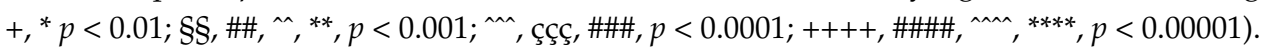

By analyzing the individual brain regions according to the disease, we observed that the CHID1 expression levels were significantly higher in NDHC than in AD in all brain regions, with the exception of the diencephalon and cingulate regions (Figure 7).

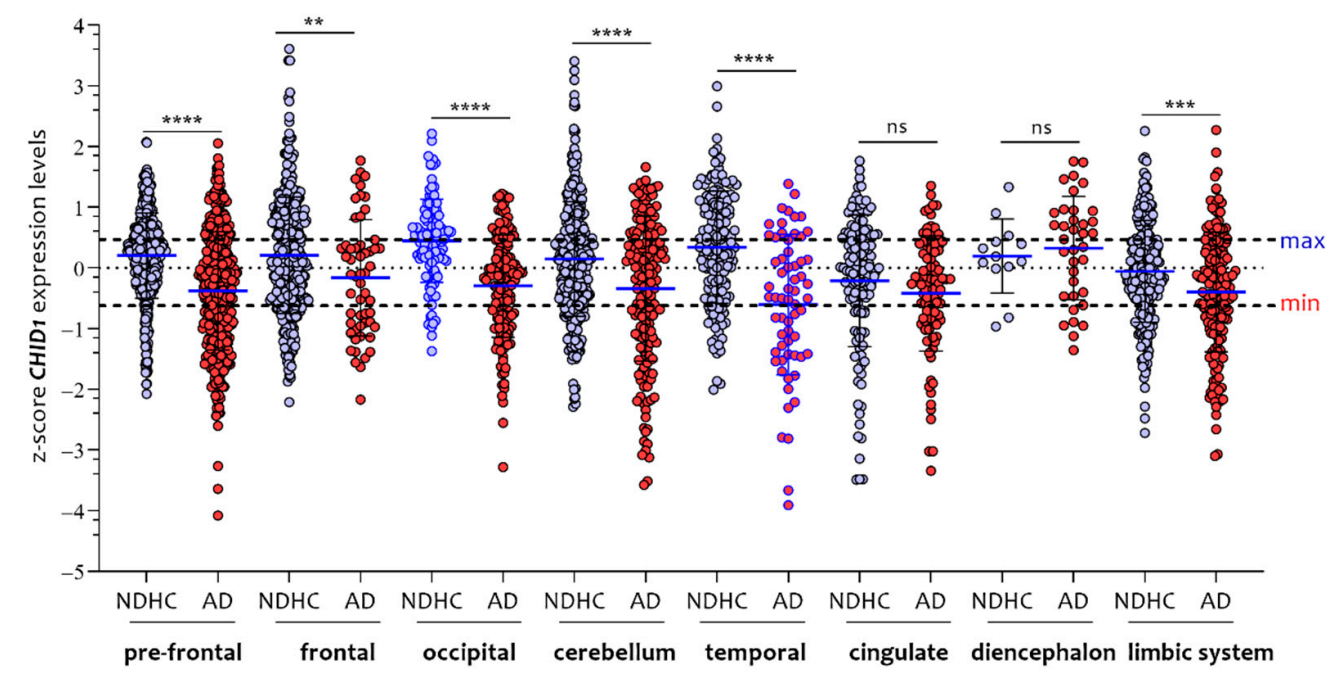

Figure 7. CHID1 expression levels comparative analysis in eight brain regions of NDHC subjects and AD patients. By analyzing the individual brain regions according to the disease, we observed that the CHID1 expression levels were significantly higher in NDHC than in AD in all brain regions, with the exception of the diencephalon and cingulate regions. Data in the figure are indicated as z-score intensity expression levels and presented graphically as violin dot plots. $p$ values $<0.05$ were considered to be statistically significant ( $\mathrm{ns}=$ not significant; ${ }^{* *} p<0.001$; ${ }^{* * *} p<0.0001$; ***** $p<0.00001)$. 
3.4. ROC Analysis Confirmed the Diagnostic Ability of CHID1 to Discriminate AD Patients from NDHC Subjects

In order to evaluate the potential diagnostic ability of CHID1 to discriminate the AD patients from NDHC subjects, we performed a receiver operating characteristic (ROC) analysis. We showed that $C H I D 1$ express a fair diagnostic ability to discriminate the $\mathrm{AD}$ from NDHC (AUC $=0.6368, p<0.0001$ ) (Figure $8 \mathrm{~A}$ ). This ability was maintained for both males $(\mathrm{AUC}=0.6440, p<0.0001)($ Figure $8 \mathrm{~B})$ and females $(\mathrm{AUC}=0.6304, p<0.0001)$ (Figure 8C).

(A)

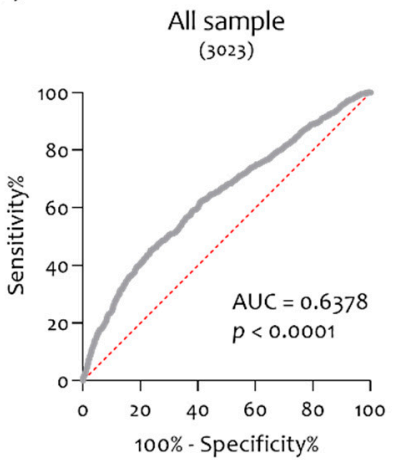

(B)

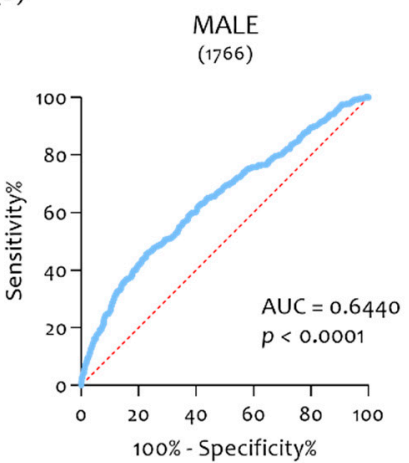

(C)

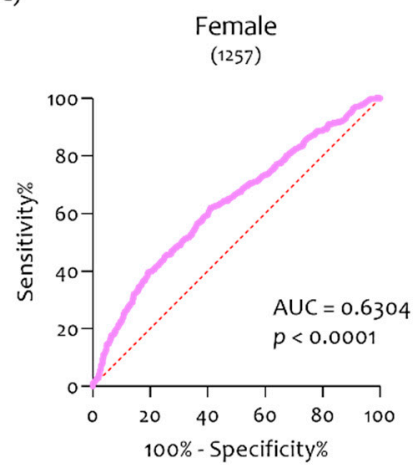

Figure 8. CHID1 brain expression levels as a prognostic marker of AD. In order to evaluate the potential diagnostic ability of CHID1 to discriminate against the AD patients from NDHC subjects, we performed a receiver operating characteristic (ROC) analysis. CHID1 expressed fair diagnostic ability (AUC $=0.6368, p<0.0001)(\mathrm{A})$. This ability was maintained for both males (AUC $=0.6440$, $p<0.0001)(\mathbf{B})$ and females (AUC $=0.6304, p<0.0001)(\mathbf{C})$.

\section{Discussion}

Here, we have shown that the gene expression of CHID1 was downregulated in the brain of AD patients compared to NDHC subjects, and both in NDHC and in AD patients, the expression levels were strongly correlated with NRGN and CALB1. Only in AD patients, the CHID1 expression levels were positively correlated with $I B A 1$ levels. A closer investigation of the CHID1 expression levels in the different brain regions showed significant correlation differences between NDHCS and AD in prefrontal, frontal, occipital, cerebellum, temporal, and limbic system. Sex-related differences in CHID1 expression were only highlighted in NDHC subjects' limbic system region in which males had significantly lower levels than females.

In recent years, the use of datasets available in public databases has grown exponentially. Several research groups, including ours, have extensively used the analysis of public transcriptome datasets for the identification of novel pathogenic pathways and therapeutic targets in several human pathologies $[25,26,89-94]$ including neurodegenerative disease $[6,12,13,25,95,96]$ and cancer $[14,97-99]$. Through a meta-analysis of public array datasets, it is possible to increase the statistical power to obtain a more precise estimate of gene expression differentials, and assess the heterogeneity of the overall estimate. Metaanalysis is relatively inexpensive since it makes comprehensive use of already available data and represents a vast source of information that could make a difference in setting up highly targeted experimental strategies.

To date, information regarding the potential role played by CHID1 in CNS has remained very poor. On the contrary, great attention has been paid to other chitinase-like proteins such as CHI3L1, CHI3L2, CHIA, and CHIT1 and their role in various inflammatory processes [100,101]. In 2016, our group demonstrated, for the first time, that the CHID1 expression levels were significantly downregulated in the brains of LOAD patients and were not related to sex [13]. In this manuscript, we have shown that CHID1 expression 
levels were significantly downregulated in $\mathrm{AD}$ patients and correlated positively with NRGN and CALB1 and negatively with IBA1 and CD31 in the brain of NDHC subjects.

Furthermore, in the 1266 brain sample biopsies of males and in the 587 of female NDHC subjects, the CHID1 expression levels were inversely correlated with age. These results are in line with the data previously observed by our group in a small cohort of samples [13]. In the past, we have speculated that CHI3L1 could play a role in the cytoskeletal structure [11,16]. Such data have also been partially verified for CHID1 [16]. Indeed, it has been shown that CHID1 suppressed macrophage cytoskeletal rearrangements in response to CCL2 [102]. Furthermore, using the online tool "The Human Protein Atlas", we have observed that CHID1 protein was localized in the nucleoplasm and in intermediate filaments. This potential interaction with the cytoskeleton could partially explain the inverse correlation with age as well as the reduction in the brain in AD subjects. Numerous studies analyzing human postmortem tissue, animal models, and cellular paradigms indicate that $\mathrm{AD}$ pathology has a deleterious effect on the pathways governing actin cytoskeleton stability [103]. These conditions have also been demonstrated during brain aging [104]. It is known that the cytoskeleton is an abundant and broadly expressed structure that plays critical functions in many cellular processes ranging from cell motility to controlling cell shape and polarity. In light of this, cytoskeleton function in neurons is crucial for the morphological changes that occur in the brain throughout life. We could hypothesize that the CHID1 expression is linked to the cytoskeleton and that it can play a role at the level of the dendritic spines. The cytoskeleton alteration mediated by CHID1 could be one of the key events contributing to the initial phases of aging in the brain or during the $\mathrm{AD}$ progression. Furthermore, we showed that both in males and females during aging, in healthy subjects and in AD patients, the expression levels of CHID1 and NRGN were closely related. There is a close relationship between NRGN and rearrangement of the cytoskeletal structures of neurons [105]. It is known that NRGN is a postsynaptic protein primarily expressed in the brain, particularly in dendritic spines. Because of its abundant and preferential neuronal expression, NRGN has been identified as a potential marker of age-related neurodegeneration. Synaptic loss is an early pathologic substrate of AD. Actually, the CSF protein levels are used as AD progression markers [106]. The strong correlation identified between CHID1 and NRGN brain expression levels allows us to hypothesize a probable common role between the two genes.

An extremely interesting result highlighted during our investigation was the strong correlation between CHID1 and CALB1 expression levels in the brain of NDHC subjects and $\mathrm{AD}$ patients. $C A L B 1$ is one of the major calcium-binding proteins that plays a critical role in preventing neuronal death as well as maintaining calcium homeostasis [41]. Decreased CALB1 expression levels represent an index of neuronal death. It has been shown that CALB1 removal from amyloid precursor protein/presenilin transgenic mice aggravates AD pathogenesis, suggesting that CALB1 has a critical role in AD pathogenesis [41]. The fact that the CHID1 and CALB1 expression levels are strongly correlated suggests not only that CHID1 is localized at the level of neurons but that it can play a role in structural maintenance. Other chitinases have already shown multifaceted functions according to the cells in which they are expressed. CHID1 could also perform different functions depending on the cellular environment in which it is expressed. Not surprisingly, in our analysis, we have observed a positive correlation between the expression levels of CHID1 and IBA1 only and exclusively at the level of the brains of AD patients, regardless of gender. This would suggest that CHID1 could be also associated with microglial activation. The association between CHID1 and macrophage lineage activation represents one of the few pieces of information currently available on the role played by this gene [25].

CHID1 brain expression levels were different in the eight brain regions analyzed. In NDHC subjects, the highest levels were in the occipital lobe, a region involved in functions linked to visual perception, while the lowest were in the cingulate cortex, a region involved in certain higher-level functions such as attention allocation, decisionmaking, morality, impulse control, and emotion. In the brains of AD patients, this trend 
was completely distorted, finding the lowest levels in the temporal region involved in processing sensory input visual memory and comprehension of language, and the highest levels in the diencephalon, which includes several regions with functions associated with recognition of the sensory impulses of heat, cold, pain, pressure, control of eye movement, and hearing responses.

Sex differences in CHID1 expression levels were observed only in the limbic system region in NDHC subjects, in which males had significantly lower levels than females. These results would suggest that CHID1 could play different roles in healthy subjects compared to AD patients, and that its function could be potentially related to the cognitive functions of the brain regions to in which it is involved.

Summing up, our analysis shows that CHID1 has an opposite trend in the CNS compared to other CLPs. Indeed, while the levels of CHI3L1 and CHI3L2 in AD patients tend to increase leading to hypothesis of a potential immunological role, CHID1 levels tend to decrease both with age and in neurological diseases such as AD. This reduction associated with both physiological and pathological aging as in AD could suggest a structural, rather than immunological, role in the neurons.

\section{Conclusions}

The biological function of CHID1 remains poorly explored and still unknown. Our manuscript has tried to partially shed light on the potential involvement of its expression in AD disease. Previously, our group identified three other chitinases involved in AD $[13,107,108]$. While the CHIT1, CHI3L1, and CHI3L2 expression levels tend to increase in the brain of AD patients, most likely because they are linked to neuroinflammation and innate immune cell activation, in the opposite manner, the CHID1 levels tend to decrease, and we hypothesized this is because they are linked to neuron death. A therapeutic strategy that significantly reduces the neuroinflammation in the brain of AD patients could consequently be reflected as a reduction in the expression levels of CHIT1, CHI3L1, and CHI3L2. Regarding the CHID1 expression levels, therapy capable of reducing or slowing neuronal death could be verified by an increase in CHID1 expression levels. Most likely, the action of CHID1 inside neurons is attributable to structural, cytoskeletal functions, but further studies are needed to prove this hypothesis. We recently hypothesized that the role of CHID1 can be also involve the nuclear level [16].

In light of this information, the sexual differences in the CHI3L1 and CHI3L2 expression levels, highlighted in e recent papers [13] and also partially found for CHID1, could open the door to targeted strategies involving gender-specific therapies. Unfortunately, as for the differential diagnosis, we cannot answer exhaustively if CHID1 is a unique marker of AD disease, but it represents an excellent starting point for further investigations in order to investigate the potential role of CHID1 in the diagnosis and progression of this disease.

Supplementary Materials: The following are available online at https:/ / www.mdpi.com/article/10 .3390/ cells10040882/s1, Figure S1: Significant difference in NDHC subjects' limbic system region.

Author Contributions: Conceptualization, M.D.R., C.S., P.C., and R.I.; Methodology, M.D.R., and C.S.; Investigation, M.D.R., C.S., P.C., R.I.; Data Curation, M.D.R. and C.S.; Writing-Original Draft, M.D.R., P.C., and C.S.; Writing-Review and Editing, M.D.R., C.S., P.C., R.I., A.C. Resources, A.C., D.L.F., D.T., M.D.R., C.S., G.M. (Giuseppe Musumeci), G.M. (Grazia Maugeri); Visualization, M.D.R.; Supervision, M.D.R., C.S., P.C. All authors have read and agreed to the published version of the manuscript.

Funding: This work was supported by the University Research Project Grant (PIACERI FoundNATUREOA-2020-2022), Department of Biomedical and Biotechnological Sciences (BIOMETEC), University of Catania, Italy.

Institutional Review Board Statement: Not applicable.

Informed Consent Statement: Not applicable. 
Data Availability Statement: The datasets analyzed during the current study are available in GeoDataset. See Table 1 for the reference.

Acknowledgments: We would like to show our gratitude to the authors of microarray datasets made available online, for consultation and re-analysis. We also want to thank the band Pink Floyd for their song "Time", which served as inspiration during manuscript writing.

Conflicts of Interest: The authors declare no conflict of interest.

\section{References}

1. Gitler, A.D.; Dhillon, P.; Shorter, J. Neurodegenerative disease: Models, mechanisms, and a new hope. Dis. Models Mech. 2017, 10, 499-502. [CrossRef] [PubMed]

2. Hou, Y.; Dan, X.; Babbar, M.; Wei, Y.; Hasselbalch, S.G.; Croteau, D.L.; Bohr, V.A. Ageing as a risk factor for neurodegenerative disease. Nat. Rev. Neurol. 2019, 15, 565-581. [CrossRef]

3. Blennow, K.; de Leon, M.J.; Zetterberg, H. Alzheimer's disease. Lancet 2006, 368, 387-403. [CrossRef]

4. Kaya, I.; Brinet, D.; Michno, W.; Baskurt, M.; Zetterberg, H.; Blenow, K.; Hanrieder, J. Novel Trimodal MALDI Imaging Mass Spectrometry (IMS3) at 10 mum Reveals Spatial Lipid and Peptide Correlates Implicated in Abeta Plaque Pathology in Alzheimer's Disease. ACS Chem. Neurosci. 2017, 8, 2778-2790. [CrossRef]

5. Frankel, R.; Tornquist, M.; Meisl, G.; Hansson, O.; Andreasson, U.; Zetterberg, H.; Blennow, K.; Frohm, B.; Cedervall, T.; Knowles, T.P.J.; et al. Autocatalytic amplification of Alzheimer-associated Abeta42 peptide aggregation in human cerebrospinal fluid. Commun. Biol. 2019, 2, 365. [CrossRef] [PubMed]

6. Sanfilippo, C.; Longo, A.; Lazzara, F.; Cambria, D.; Distefano, G.; Palumbo, M.; Cantarella, A.; Malaguarnera, L.; Di Rosa, M. CHI3L1 and CHI3L2 overexpression in motor cortex and spinal cord of sALS patients. Mol. Cell. Neurosci. 2017, 85, 162-169. [CrossRef]

7. Zhou, Y.; Li, X.; Yuan, X.; Hao, L. Role of allograft inflammatory factor-1 in the regulation of inflammation and oxidative stress in primary peritoneal mesothelial cells. Cell Biol. Int. 2019, 43, 495-505. [CrossRef] [PubMed]

8. Kalinowska, A.; Losy, J. PECAM-1, a key player in neuroinflammation. Eur. J. Neurol. 2006, 13, 1284-1290. [CrossRef]

9. Fairless, R.; Williams, S.K.; Diem, R. Calcium-Binding Proteins as Determinants of Central Nervous System Neuronal Vulnerability to Disease. Int. J. Mol. Sci 2019, 20, 2146. [CrossRef] [PubMed]

10. Di Rosa, M.; De Gregorio, C.; Malaguarnera, G.; Tuttobene, M.; Biazzo, F.; Malaguarnera, L. Evaluation of AMCase and CHIT-1 expression in monocyte macrophages lineage. Mol. Cell. Biochem. 2013, 374, 73-80. [CrossRef]

11. Di Rosa, M.; Tibullo, D.; Cambria, D.; Distefano, G.; Saccone, S.; Di Raimondo, F.; Malaguarnera, L. Chitotriosidase Expression during Monocyte-Derived Dendritic Cells Differentiation and Maturation. Inflammation 2015, 38, 2082-2091. [CrossRef]

12. Sanfilippo, C.; Castrogiovanni, P.; Imbesi, R.; Kazakowa, M.; Musumeci, G.; Blennow, K.; Zetterberg, H.; Di Rosa, M. Sex difference in CHI3L1 expression levels in human brain aging and in Alzheimer's disease. Brain Res. 2019, 1720, 146305. [CrossRef]

13. Sanfilippo, C.; Malaguarnera, L.; Di Rosa, M. Chitinase expression in Alzheimer's disease and non-demented brains regions. J. Neurol. Sci. 2016, 369, 242-249. [CrossRef]

14. Di Rosa, M.; Sanfilippo, C.; Libra, M.; Musumeci, G.; Malaguarnera, L. Different pediatric brain tumors are associated with different gene expression profiling. Acta Histochem. 2015, 117, 477-485. [CrossRef]

15. Di Rosa, M.; Malaguarnera, G.; De Gregorio, C.; Drago, F.; Malaguarnera, L. Evaluation of CHI3L-1 and CHIT-1 expression in differentiated and polarized macrophages. Inflammation 2013, 36, 482-492. [CrossRef] [PubMed]

16. Di Rosa, M.; Tibullo, D.; Saccone, S.; Distefano, G.; Basile, M.S.; Di Raimondo, F.; Malaguarnera, L. CHI3L1 nuclear localization in monocyte derived dendritic cells. Immunobiology 2016, 221, 347-356. [CrossRef]

17. Di Rosa, M.; Tibullo, D.; Vecchio, M.; Nunnari, G.; Saccone, S.; Di Raimondo, F.; Malaguarnera, L. Determination of chitinases family during osteoclastogenesis. Bone 2014, 61, 55-63. [CrossRef]

18. Qiu, Q.C.; Wang, L.; Jin, S.S.; Liu, G.F.; Liu, J.; Ma, L.; Mao, R.F.; Ma, Y.Y.; Zhao, N.; Chen, M.; et al. CHI3L1 promotes tumor progression by activating TGF-beta signaling pathway in hepatocellular carcinoma. Sci. Rep. 2018, 8, 15029. [CrossRef]

19. Di Rosa, M.; Zambito, A.M.; Marsullo, A.R.; Li Volti, G.; Malaguarnera, L. Prolactin induces chitotriosidase expression in human macrophages through PTK, PI3-K., and MAPK pathways. J. Cell. Biochem. 2009, 107, 881-889. [CrossRef]

20. Di Rosa, M.; Malaguarnera, L. Genetic variants in candidate genes influencing NAFLD progression. J. Mol. Med. 2012, 90, 105-118. [CrossRef]

21. Di Rosa, M.; Malaguarnera, L. Chitinase 3 Like-1: An Emerging Molecule Involved in Diabetes and Diabetic Complications. Pathobiology 2016, 83, 228-242. [CrossRef]

22. Di Rosa, M.; Szychlinska, M.A.; Tibullo, D.; Malaguarnera, L.; Musumeci, G. Expression of CHI3L1 and CHIT1 in osteoarthritic rat cartilage model. A morphological study. Eur. J. Histochem. EJH 2014, 58, 2423. [CrossRef]

23. Kwak, E.J.; Hong, J.Y.; Kim, M.N.; Kim, S.Y.; Kim, S.H.; Park, C.O.; Kim, K.W.; Lee, C.G.; Elias, J.A.; Jee, H.M.; et al. Chitinase 3-like 1 drives allergic skin inflammation via Th2 immunity and M2 macrophage activation. Clin. Exp. Allergy J. Br. Soc. Allergy Clin. Immunol. 2019, 49, 1464-1474. [CrossRef]

24. Kzhyshkowska, J.; Gratchev, A.; Goerdt, S. Stabilin-1, a homeostatic scavenger receptor with multiple functions. J. Cell. Mol. Med. 2006, 10, 635-649. [CrossRef] [PubMed] 
25. Sanfilippo, C.; Nunnari, G.; Calcagno, A.; Malaguarnera, L.; Blennow, K.; Zetterberg, H.; Di Rosa, M. The chitinases expression is related to Simian Immunodeficiency Virus Encephalitis (SIVE) and in HIV encephalitis (HIVE). Virus Res. 2017, 227, 220-230. [CrossRef]

26. Fagone, P.; Nunnari, G.; Lazzara, F.; Longo, A.; Cambria, D.; Distefano, G.; Palumbo, M.; Nicoletti, F.; Malaguarnera, L.; Di Rosa, M. Induction of OAS gene family in HIV monocyte infected patients with high and low viral load. Antivir. Res. 2016, 131, 66-73. [CrossRef]

27. Thul, P.J.; Lindskog, C. The human protein atlas: A spatial map of the human proteome. Protein Sci. Publ. Protein Soc. 2018, 27, 233-244. [CrossRef]

28. Yang, Z.F.; Ho, D.W.; Lau, C.K.; Lam, C.T.; Lum, C.T.; Poon, R.T.; Fan, S.T. Allograft inflammatory factor-1 (AIF-1) is crucial for the survival and pro-inflammatory activity of macrophages. Int. Immunol. 2005, 17, 1391-1397. [CrossRef] [PubMed]

29. Del Galdo, F.; Maul, G.G.; Jimenez, S.A.; Artlett, C.M. Expression of allograft inflammatory factor 1 in tissues from patients with systemic sclerosis and in vitro differential expression of its isoforms in response to transforming growth factor beta. Arthritis Rheum. 2006, 54, 2616-2625. [CrossRef]

30. Reus, G.Z.; Silva, R.H.; de Moura, A.B.; Presa, J.F.; Abelaira, H.M.; Abatti, M.; Vieira, A.; Pescador, B.; Michels, M.; Ignacio, Z.M.; et al. Early Maternal Deprivation Induces Microglial Activation, Alters Glial Fibrillary Acidic Protein Immunoreactivity and Indoleamine 2,3-Dioxygenase during the Development of Offspring Rats. Mol. Neurobiol. 2019, 56, 1096-1108. [CrossRef] [PubMed]

31. Yamamoto, A.; Kawahito, Y. The immunologic function and role of allograft inflammatory factor-1. Nihon Rinsho Men'eki Gakkai Kaishi Jpn. J. Clin. Immunol. 2014, 37, 139-145. [CrossRef]

32. Schwab, J.M.; Frei, E.; Klusman, I.; Schnell, L.; Schwab, M.E.; Schluesener, H.J. AIF-1 expression defines a proliferating and alert microglial/macrophage phenotype following spinal cord injury in rats. J. Neuroimmunol. 2001, 119, 214-222. [CrossRef]

33. Giorgetti, E.; Panesar, M.; Zhang, Y.; Joller, S.; Ronco, M.; Obrecht, M.; Lambert, C.; Accart, N.; Beckmann, N.; Doelemeyer, A.; et al. Modulation of Microglia by Voluntary Exercise or CSF1R Inhibition Prevents Age-Related Loss of Functional Motor Units. Cell Rep. 2019, 29, 1539-1554.e7. [CrossRef]

34. Privratsky, J.R.; Newman, P.J. PECAM-1: Regulator of endothelial junctional integrity. Cell Tissue Res. 2014, 355, 607-619. [CrossRef] [PubMed]

35. Wimmer, I.; Tietz, S.; Nishihara, H.; Deutsch, U.; Sallusto, F.; Gosselet, F.; Lyck, R.; Muller, W.A.; Lassmann, H.; Engelhardt, B. PECAM-1 Stabilizes Blood-Brain Barrier Integrity and Favors Paracellular T-Cell Diapedesis Across the Blood-Brain Barrier During Neuroinflammation. Front. Immunol. 2019, 10, 711. [CrossRef] [PubMed]

36. Hochstrasser, T.; Weiss, E.; Marksteiner, J.; Humpel, C. Soluble cell adhesion molecules in monocytes of Alzheimer's disease and mild cognitive impairment. Exp. Gerontol. 2010, 45, 70-74. [CrossRef] [PubMed]

37. Nakagawa, S.; Castro, V.; Toborek, M. Infection of human pericytes by HIV-1 disrupts the integrity of the blood-brain barrier. J. Cell. Mol. Med. 2012, 16, 2950-2957. [CrossRef]

38. Limaos, E.A.; Borges, D.R.; Souza-Pinto, J.C.; Gordon, A.H.; Prado, J.L. Acute turpentine inflammation and kinin release in rat-paw thermic oedema. Br. J. Exp. Pathol. 1981, 62, 591-594.

39. Kiyama, H.; Seto-Ohshima, A.; Emson, P.C. Calbindin D28K as a marker for the degeneration of the striatonigral pathway in Huntington's disease. Brain Res. 1990, 525, 209-214. [CrossRef]

40. Yuan, H.H.; Chen, R.J.; Zhu, Y.H.; Peng, C.L.; Zhu, X.R. The neuroprotective effect of overexpression of calbindin-D(28k) in an animal model of Parkinson's disease. Mol. Neurobiol. 2013, 47, 117-122. [CrossRef]

41. Kook, S.Y.; Jeong, H.; Kang, M.J.; Park, R.; Shin, H.J.; Han, S.H.; Son, S.M.; Song, H.; Baik, S.H.; Moon, M.; et al. Crucial role of calbindin-D28k in the pathogenesis of Alzheimer's disease mouse model. Cell Death Differ. 2014, 21, 1575-1587. [CrossRef]

42. Masliah, E.; Ge, N.; Achim, C.L.; Wiley, C.A. Differential vulnerability of calbindin-immunoreactive neurons in HIV encephalitis. J. Neuropathol. Exp. Neurol. 1995, 54, 350-357. [CrossRef] [PubMed]

43. Dumurgier, J.; Schraen, S.; Gabelle, A.; Vercruysse, O.; Bombois, S.; Laplanche, J.L.; Peoc'h, K.; Sablonniere, B.; Kastanenka, K.V.; Delaby, C.; et al. Cerebrospinal fluid amyloid-beta $42 / 40$ ratio in clinical setting of memory centers: A multicentric study. Alzheimer's Res. Ther. 2015, 7, 30. [CrossRef]

44. Diez-Guerra, F.J. Neurogranin, a link between calcium/calmodulin and protein kinase $C$ signaling in synaptic plasticity. IUBMB Life 2010, 62, 597-606. [CrossRef] [PubMed]

45. Singec, I.; Knoth, R.; Ditter, M.; Volk, B.; Frotscher, M. Neurogranin is expressed by principal cells but not interneurons in the rodent and monkey neocortex and hippocampus. J. Comp. Neurol. 2004, 479, 30-42. [CrossRef]

46. Colom-Cadena, M.; Spires-Jones, T.; Zetterberg, H.; Blennow, K.; Caggiano, A.; DeKosky, S.T.; Fillit, H.; Harrison, J.E.; Schneider, L.S.; Scheltens, P.; et al. The clinical promise of biomarkers of synapse damage or loss in Alzheimer's disease. Alzheimer's Res. Ther. 2020, 12, 21. [CrossRef]

47. Davidsson, P.; Blennow, K. Neurochemical dissection of synaptic pathology in Alzheimer's disease. Int. Psychogeriatr. 1998, 10, 11-23. [CrossRef]

48. Reddy, P.H.; Mani, G.; Park, B.S.; Jacques, J.; Murdoch, G.; Whetsell, W., Jr.; Kaye, J.; Manczak, M. Differential loss of synaptic proteins in Alzheimer's disease: Implications for synaptic dysfunction. J. Alzheimer's Dis. JAD 2005, 7, 103-117. [CrossRef] [PubMed] 
49. Hellwig, K.; Kvartsberg, H.; Portelius, E.; Andreasson, U.; Oberstein, T.J.; Lewczuk, P.; Blennow, K.; Kornhuber, J.; Maler, J.M.; Zetterberg, H.; et al. Neurogranin and YKL-40: Independent markers of synaptic degeneration and neuroinflammation in Alzheimer's disease. Alzheimer's Res. Ther. 2015, 7, 74. [CrossRef]

50. Sjostedt, E.; Zhong, W.; Fagerberg, L.; Karlsson, M.; Mitsios, N.; Adori, C.; Oksvold, P.; Edfors, F.; Limiszewska, A.; Hikmet, F.; et al. An atlas of the protein-coding genes in the human, pig, and mouse brain. Science 2020, 367. [CrossRef]

51. Narayanan, M.; Huynh, J.L.; Wang, K.; Yang, X.; Yoo, S.; McElwee, J.; Zhang, B.; Zhang, C.; Lamb, J.R.; Xie, T.; et al. Common dysregulation network in the human prefrontal cortex underlies two neurodegenerative diseases. Mol. Syst. Biol. 2014, 10, 743. [CrossRef]

52. Kumaran, R.; Cookson, M.R. Pathways to Parkinsonism Redux: Convergent pathobiological mechanisms in genetics of Parkinson's disease. Hum. Mol. Genet. 2015, 24, R32-R44. [CrossRef]

53. Chen, C.; Meng, Q.; Xia, Y.; Ding, C.; Wang, L.; Dai, R.; Cheng, L.; Gunaratne, P.; Gibbs, R.A.; Min, S.; et al. The transcription factor POU3F2 regulates a gene coexpression network in brain tissue from patients with psychiatric disorders. Sci. Transl. Med. 2018, 10. [CrossRef]

54. Gibbs, J.R.; van der Brug, M.P.; Hernandez, D.G.; Traynor, B.J.; Nalls, M.A.; Lai, S.L.; Arepalli, S.; Dillman, A.; Rafferty, I.P.; Troncoso, J.; et al. Abundant quantitative trait loci exist for DNA methylation and gene expression in human brain. PLoS Genet. 2010, 6, e1000952. [CrossRef] [PubMed]

55. Zhang, B.; Gaiteri, C.; Bodea, L.G.; Wang, Z.; McElwee, J.; Podtelezhnikov, A.A.; Zhang, C.; Xie, T.; Tran, L.; Dobrin, R.; et al. Integrated systems approach identifies genetic nodes and networks in late-onset Alzheimer's disease. Cell 2013, 153, 707-720. [CrossRef]

56. Hernandez, D.G.; Nalls, M.A.; Moore, M.; Chong, S.; Dillman, A.; Trabzuni, D.; Gibbs, J.R.; Ryten, M.; Arepalli, S.; Weale, M.E.; et al. Integration of GWAS SNPs and tissue specific expression profiling reveal discrete eQTLs for human traits in blood and brain. Neurobiol. Dis. 2012, 47, 20-28. [CrossRef] [PubMed]

57. Trabzuni, D.; Ramasamy, A.; Imran, S.; Walker, R.; Smith, C.; Weale, M.E.; Hardy, J.; Ryten, M.; North American Brain Expression, C. Widespread sex differences in gene expression and splicing in the adult human brain. Nat. Commun. 2013, 4, 2771. [CrossRef] [PubMed]

58. Patel, H.; Hodges, A.K.; Curtis, C.; Lee, S.H.; Troakes, C.; Dobson, R.J.B.; Newhouse, S.J. Transcriptomic analysis of probable asymptomatic and symptomatic alzheimer brains. Brain Behav. Immun. 2019, 80, 644-656. [CrossRef]

59. Kang, H.J.; Kawasawa, Y.I.; Cheng, F.; Zhu, Y.; Xu, X.; Li, M.; Sousa, A.M.; Pletikos, M.; Meyer, K.A.; Sedmak, G.; et al. Spatio-temporal transcriptome of the human brain. Nature 2011, 478, 483-489. [CrossRef] [PubMed]

60. French, L.; Ma, T.; Oh, H.; Tseng, G.C.; Sibille, E. Age-Related Gene Expression in the Frontal Cortex Suggests Synaptic Function Changes in Specific Inhibitory Neuron Subtypes. Front. Aging Neurosci. 2017, 9, 162. [CrossRef]

61. Ryan, M.M.; Lockstone, H.E.; Huffaker, S.J.; Wayland, M.T.; Webster, M.J.; Bahn, S. Gene expression analysis of bipolar disorder reveals downregulation of the ubiquitin cycle and alterations in synaptic genes. Mol. Psychiatry 2006, 11, 965-978. [CrossRef]

62. Hokama, M.; Oka, S.; Leon, J.; Ninomiya, T.; Honda, H.; Sasaki, K.; Iwaki, T.; Ohara, T.; Sasaki, T.; LaFerla, F.M.; et al. Altered expression of diabetes-related genes in Alzheimer's disease brains: The Hisayama study. Cereb. Cortex 2014, 24, 2476-2488. [CrossRef]

63. Durrenberger, P.F.; Fernando, F.S.; Kashefi, S.N.; Bonnert, T.P.; Seilhean, D.; Nait-Oumesmar, B.; Schmitt, A.; Gebicke-Haerter, P.J.; Falkai, P.; Grunblatt, E.; et al. Common mechanisms in neurodegeneration and neuroinflammation: A BrainNet Europe gene expression microarray study. J. Neural Transm. 2015, 122, 1055-1068. [CrossRef]

64. Wang, M.; Roussos, P.; McKenzie, A.; Zhou, X.; Kajiwara, Y.; Brennand, K.J.; De Luca, G.C.; Crary, J.F.; Casaccia, P.; Buxbaum, J.D.; et al. Integrative network analysis of nineteen brain regions identifies molecular signatures and networks underlying selective regional vulnerability to Alzheimer's disease. Genome Med. 2016, 8, 104. [CrossRef]

65. Liang, W.S.; Dunckley, T.; Beach, T.G.; Grover, A.; Mastroeni, D.; Walker, D.G.; Caselli, R.J.; Kukull, W.A.; McKeel, D.; Morris, J.C.; et al. Gene expression profiles in anatomically and functionally distinct regions of the normal aged human brain. Physiol. Genom. 2007, 28, 311-322. [CrossRef] [PubMed]

66. Berchtold, N.C.; Cribbs, D.H.; Coleman, P.D.; Rogers, J.; Head, E.; Kim, R.; Beach, T.; Miller, C.; Troncoso, J.; Trojanowski, J.Q.; et al. Gene expression changes in the course of normal brain aging are sexually dimorphic. Proc. Natl. Acad. Sci. USA 2008, 105, 15605-15610. [CrossRef] [PubMed]

67. Berchtold, N.C.; Coleman, P.D.; Cribbs, D.H.; Rogers, J.; Gillen, D.L.; Cotman, C.W. Synaptic genes are extensively downregulated across multiple brain regions in normal human aging and Alzheimer's disease. Neurobiol. Aging 2013, 34, 1653-1661. [CrossRef]

68. Blalock, E.M.; Buechel, H.M.; Popovic, J.; Geddes, J.W.; Landfield, P.W. Microarray analyses of laser-captured hippocampus reveal distinct gray and white matter signatures associated with incipient Alzheimer's disease. J. Chem. Neuroanat. 2011, 42, 118-126. [CrossRef]

69. Xiao, J.; Cao, H.; Chen, J. False discovery rate control incorporating phylogenetic tree increases detection power in microbiomewide multiple testing. Bioinformatics 2017, 33, 2873-2881. [CrossRef] [PubMed]

70. Smyth, G.K. Linear models and empirical bayes methods for assessing differential expression in microarray experiments. Stat. Appl. Genet. Mol. Biol. 2004, 3. [CrossRef] [PubMed]

71. Davis, S.; Meltzer, P.S. GEOquery: A bridge between the Gene Expression Omnibus (GEO) and BioConductor. Bioinformatics 2007, 23, 1846-1847. [CrossRef] 
72. Mauri, E.; Sacchetti, A.; Vicario, N.; Peruzzotti-Jametti, L.; Rossi, F.; Pluchino, S. Evaluation of RGD functionalization in hybrid hydrogels as 3D neural stem cell culture systems. Biomater. Sci. 2018, 6, 501-510. [CrossRef]

73. Box, G.E.; Tiao, G.C. Bayesian Inference in Statistical Analysis; John Wiley \& Sons: Hoboken, NJ, USA, 1992. [CrossRef]

74. Cheadle, C.; Vawter, M.P.; Freed, W.J.; Becker, K.G. Analysis of microarray data using Z score transformation. J. Mol. Diagn. 2003, 5, 73-81. [CrossRef]

75. Scarpino, M.; Pinzone, M.R.; Di Rosa, M.; Madeddu, G.; Foca, E.; Martellotta, F.; Schioppa, O.; Ceccarelli, G.; Celesia, B.M.; d'Ettorre, G.; et al. Kidney disease in HIV-infected patients. Eur. Rev. Med. Pharmacol. Sci. 2013, 17, $2660-2667$.

76. Care, M.A.; Barrans, S.; Worrillow, L.; Jack, A.; Westhead, D.R.; Tooze, R.M. A microarray platform-independent classification tool for cell of origin class allows comparative analysis of gene expression in diffuse large B-cell lymphoma. PLoS ONE 2013, 8, e55895. [CrossRef]

77. Wang, J.; Coombes, K.R.; Highsmith, W.E.; Keating, M.J.; Abruzzo, L.V. Differences in gene expression between B-cell chronic lymphocytic leukemia and normal B cells: A meta-analysis of three microarray studies. Bioinformatics 2004, 20, 3166-3178. [CrossRef] [PubMed]

78. Reddy, T.B.; Riley, R.; Wymore, F.; Montgomery, P.; DeCaprio, D.; Engels, R.; Gellesch, M.; Hubble, J.; Jen, D.; Jin, H.; et al. TB database: An integrated platform for tuberculosis research. Nucleic Acids Res. 2009, 37, D499-D508. [CrossRef] [PubMed]

79. Le Cao, K.A.; Rohart, F.; McHugh, L.; Korn, O.; Wells, C.A. YuGene: A simple approach to scale gene expression data derived from different platforms for integrated analyses. Genomics 2014, 103, 239-251. [CrossRef]

80. Chen, Q.R.; Song, Y.K.; Wei, J.S.; Bilke, S.; Asgharzadeh, S.; Seeger, R.C.; Khan, J. An integrated cross-platform prognosis study on neuroblastoma patients. Genomics 2008, 92, 195-203. [CrossRef] [PubMed]

81. Yasrebi, H.; Sperisen, P.; Praz, V.; Bucher, P. Can survival prediction be improved by merging gene expression data sets? PLoS ONE 2009, 4, e7431. [CrossRef]

82. Mehmood, R.; El-Ashram, S.; Bie, R.; Dawood, H.; Kos, A. Clustering by fast search and merge of local density peaks for gene expression microarray data. Sci. Rep. 2017, 7, 45602. [CrossRef]

83. Cheadle, C.; Cho-Chung, Y.S.; Becker, K.G.; Vawter, M.P. Application of z-score transformation to Affymetrix data. Appl. Bioinform. 2003, 2, 209-217.

84. Feng, C.; Wu, J.; Yang, F.; Qiu, M.; Hu, S.; Guo, S.; Wu, J.; Ying, X.; Wang, J. Expression of Bcl-2 is a favorable prognostic biomarker in lung squamous cell carcinoma. Oncol. Lett. 2018, 15, 6925-6930. [CrossRef] [PubMed]

85. Kang, C.; Huo, Y.; Xin, L.; Tian, B.; Yu, B. Feature selection and tumor classification for microarray data using relaxed Lasso and generalized multi-class support vector machine. J. Biol. 2019, 463, 77-91. [CrossRef] [PubMed]

86. Gulino, R.; Vicario, N.; Giunta, M.A.S.; Spoto, G.; Calabrese, G.; Vecchio, M.; Gulisano, M.; Leanza, G.; Parenti, R. Neuromuscular Plasticity in a Mouse Neurotoxic Model of Spinal Motoneuronal Loss. Int. J. Mol. Sci. 2019, 20, 1500. [CrossRef] [PubMed]

87. Vicario, N.; Bernstock, J.D.; Spitale, F.M.; Giallongo, C.; Giunta, M.A.S.; Li Volti, G.; Gulisano, M.; Leanza, G.; Tibullo, D.; Parenti, R.; et al. Clobetasol Modulates Adult Neural Stem Cell Growth via Canonical Hedgehog Pathway Activation. Int. J. Mol. Sci. 2019, 20, 1991. [CrossRef]

88. Zetterberg, H.; Bozzetta, E.; Favole, A.; Corona, C.; Cavarretta, M.C.; Ingravalle, F.; Blennow, K.; Pocchiari, M.; Meloni, D. Neurofilaments in blood is a new promising preclinical biomarker for the screening of natural scrapie in sheep. PLoS ONE 2019, 14, e0226697. [CrossRef]

89. Catrogiovanni, P.; Musumeci, G.; Giunta, S.; Imbesi, R.; Di Rosa, M. The expression levels of CHI3L1 and IL15Ralpha correlate with TGM2 in duodenum biopsies of patients with celiac disease. Inflamm. Res. 2020, 69, 925-935. [CrossRef]

90. Musumeci, G.; Castrogiovanni, P.; Barbagallo, I.; Tibullo, D.; Sanfilippo, C.; Nunnari, G.; Pellicano, G.F.; Pavone, P.; Caltabiano, R.; Di Marco, R.; et al. Expression of the OAS Gene Family Is Highly Modulated in Subjects Affected by Juvenile Dermatomyositis, Resembling an Immune Response to a dsRNA Virus Infection. Int. J. Mol. Sci. 2018, 19, 2786. [CrossRef]

91. Sanfilippo, C.; Pinzone, M.R.; Cambria, D.; Longo, A.; Palumbo, M.; Di Marco, R.; Condorelli, F.; Nunnari, G.; Malaguarnera, L.; Di Rosa, M. OAS Gene Family Expression Is Associated with HIV-Related Neurocognitive Disorders. Mol. Neurobiol. 2018, 55, 1905-1914. [CrossRef]

92. Fagone, P.; Di Rosa, M.; Palumbo, M.; De Gregorio, C.; Nicoletti, F.; Malaguarnera, L. Modulation of heat shock proteins during macrophage differentiation. Inflamm. Res. 2012, 61, 1131-1139. [CrossRef] [PubMed]

93. Caltabiano, R.; Castrogiovanni, P.; Barbagallo, I.; Ravalli, S.; Szychlinska, M.A.; Favilla, V.; Schiavo, L.; Imbesi, R.; Musumeci, G.; Di Rosa, M. Identification of Novel Markers of Prostate Cancer Progression, Potentially Modulated by Vitamin D. Appl. Sci. 2019, 9, 4923. [CrossRef]

94. Nunnari, G.; Sanfilippo, C.; Castrogiovanni, P.; Imbesi, R.; Li Volti, G.; Barbagallo, I.; Musumeci, G.; Di Rosa, M. Network perturbation analysis in human bronchial epithelial cells following SARS-CoV2 infection. Exp. Cell Res. 2020, 395, 112204. [CrossRef]

95. Sanfilippo, C.; Castrogiovanni, P.; Imbesi, R.; Tibullo, D.; Li Volti, G.; Barbagallo, I.; Vicario, N.; Musumeci, G.; Di Rosa, M. Middle-aged healthy women and Alzheimer's disease patients present an overlapping of brain cell transcriptional profile. Neuroscience 2019, 406, 333-344. [CrossRef]

96. Castrogiovanni, P.; Li Volti, G.; Sanfilippo, C.; Tibullo, D.; Galvano, F.; Vecchio, M.; Avola, R.; Barbagallo, I.; Malaguarnera, L.; Castorina, S.; et al. Fasting and Fast Food Diet Play an Opposite Role in Mice Brain Aging. Mol. Neurobiol. 2018, 55, 6881-6893. [CrossRef] 
97. D'Andrea, F.; Rullo, E.V.; Facciola, A.; Di Rosa, M.; Condorelli, F.; Marino, A.; Cacopardo, B.; Pellicano, G.F.; Nunnari, G.; Ceccarelli, M. Epstein Barr Virus related cancer in people living with HIV: A review of the literature. World Cancer Res. J. 2020, 7, e1512.

98. Giallongo, S.; Di Rosa, M.; Caltabiano, R.; Longhitano, L.; Reibaldi, M.; Distefano, A.; Lo Re, O.; Amorini, A.M.; Puzzo, L.; Salvatorelli, L.; et al. Loss of macroH2A1 decreases mitochondrial metabolism and reduces the aggressiveness of uveal melanoma cells. Aging 2020, 12, 9745-9760. [CrossRef] [PubMed]

99. Malaguarnera, L.; Nunnari, G.; Di Rosa, M. Nuclear import sequence identification in hOAS3 protein. Inflamm. Res. 2016, 65, 895-904. [CrossRef]

100. Tibullo, D.; Di Rosa, M.; Giallongo, C.; La Cava, P.; Parrinello, N.L.; Romano, A.; Conticello, C.; Brundo, M.V.; Saccone, S.; Malaguarnera, L.; et al. Bortezomib modulates CHIT1 and YKL40 in monocyte-derived osteoclast and in myeloma cells. Front. Pharmacol. 2015, 6, 226. [CrossRef] [PubMed]

101. Szychlinska, M.A.; Trovato, F.M.; Di Rosa, M.; Malaguarnera, L.; Puzzo, L.; Leonardi, R.; Castrogiovanni, P.; Musumeci, G. Co-Expression and Co-Localization of Cartilage Glycoproteins CHI3L1 and Lubricin in Osteoarthritic Cartilage: Morphological, Immunohistochemical and Gene Expression Profiles. Int. J. Mol. Sci. 2016, 17, 359. [CrossRef] [PubMed]

102. Yin, S.; Wang, N.; Riabov, V.; Mossel, D.M.; Larionova, I.; Schledzewski, K.; Trofimova, O.; Sevastyanova, T.; Zajakina, A.; Schmuttermaier, C.; et al. SI-CLP inhibits the growth of mouse mammary adenocarcinoma by preventing recruitment of tumor-associated macrophages. Int. J. Cancer 2020, 146, 1396-1408. [CrossRef]

103. Penzes, P.; Vanleeuwen, J.E. Impaired regulation of synaptic actin cytoskeleton in Alzheimer's disease. Brain Res. Rev. 2011, 67, 184-192. [CrossRef] [PubMed]

104. Mack, T.G.; Kreis, P.; Eickholt, B.J. Defective actin dynamics in dendritic spines: Cause or consequence of age-induced cognitive decline? Biol. Chem. 2016, 397, 223-229. [CrossRef]

105. Gao, Y.; Tatavarty, V.; Korza, G.; Levin, M.K.; Carson, J.H. Multiplexed dendritic targeting of alpha calcium calmodulin-dependent protein kinase II, neurogranin, and activity-regulated cytoskeleton-associated protein RNAs by the A2 pathway. Mol. Biol. Cell 2008, 19, 2311-2327. [CrossRef] [PubMed]

106. Thorsell, A.; Bjerke, M.; Gobom, J.; Brunhage, E.; Vanmechelen, E.; Andreasen, N.; Hansson, O.; Minthon, L.; Zetterberg, H.; Blennow, K. Neurogranin in cerebrospinal fluid as a marker of synaptic degeneration in Alzheimer's disease. Brain Res. 2010, 1362, 13-22. [CrossRef] [PubMed]

107. Sanfilippo, C.; Castrogiovanni, P.; Imbesi, R.; Di Rosa, M. CHI3L2 Expression Levels Are Correlated with AIF1, PECAM1, and CALB1 in the Brains of Alzheimer's Disease Patients. J. Mol. Neurosci. 2020, 70, 1598-1610. [CrossRef] [PubMed]

108. Di Rosa, M.; Dell'Ombra, N.; Zambito, A.M.; Malaguarnera, M.; Nicoletti, F.; Malaguarnera, L. Chitotriosidase and inflammatory mediator levels in Alzheimer's disease and cerebrovascular dementia. Eur. J. Neurosci. 2006, 23, 2648-2656. [CrossRef] 